\title{
Fertility Desire and Associated Factors among People Living with HIV on ART, In Harari Regional State, Eastern Ethiopia
}

Fisaha Haile $^{1^{\star}}$, Nesredine Isahak ${ }^{2}$ and Awrajaw Dessie ${ }^{1}$

${ }^{1}$ Mekelle University, College of Health Science, Department of Public Health, Mekelle, Ethiopia

${ }^{2}$ Harari Regional Health Bureau, Harar-Ethiopia

"Corresponding author: Fisaha Haile, Mekelle University, College of Health Science, Department of Public Health, Mekelle, Ethiopia, Tel: 251913340013; Fax: 2513444166775; E-mail: fisaha.1999@yahoo.com

Rec date: Apr 04, 2014; Acc date: May 02, 2014; Pub date: May 5, 2014

Copyright: @ 2014 Haile F, et al. This is an open-access article distributed under the terms of the Creative Commons Attribution License, which permits unrestricted use, distribution, and reproduction in any medium, provided the original author and source are credited.

\begin{abstract}
Background: Now a days, studies have shown that HIV infection may affect fertility by influencing desires and intentions to have children. On the other hand, studies of fertility intentions among HIV-positive individuals have suffered ambivalence and mixed results while some studies report a strong desire to have children, consistent with the high social values placed on children and others doesn't. The relative strength of these conflicting findings varies according to individual and contextual factors. So, the aim of this study was to determine the magnitude of fertility desire and factors affecting it.
\end{abstract}

Method: A facility based cross-sectional study design was conducted among 518 individuals on ART from February to March 2013. A stratified systematic sampling by sex with proportional to size was employed to select the study subjects. Bivariate logistic regression was done to see the crude relationship and finally multiple logistic regressions were employed to identify the independent predictors of fertility desire.

Result: More than half $(56.2 \%)$ of people living with HIV have fertility desire. Women have $58 \%$ times lesser fertility desire than men likewise age group 30-39 and Age $>=40$ have $61 \%$ and $85 \%$ times lesser fertility desire than 18-29 years respectively. Additionally, individuals who have a child in their life time have $76 \%$ times lesser desire than those who doesn't ever have. Those who were not using family planning were three times higher to desire for a child than their counter parts and respondents who were not sexually active in the last six months have $77 \%$ times lesser fertility desire than those who were not.

Conclusions: High proportion of people living with HIV had fertility desire. Sex, Age, presence of children in their life time, use of family planning and sexual activity in the last six months were factors that affect fertility desire. Consequently, this implies the need for comprehensive reproductive planning and counseling for clients in HIV care settings in order to meet diverse reproductive intentions of PLWHIV.

Keywords: HIV and fertility; ART and fertility; Fertility and AIDS

\section{Introduction}

Now a days, studies have shown that HIV infection may affect fertility by influencing desires and intentions for having children. On the other hand studies of fertility intentions among HIV-positive individuals have found ambivalence and mixed results while some studies reporting a strong desire to have children, consistent with the high social value placed on children and others doesn't. The relative strength of these conflicting findings varies according to individual and contextual factors. For instance unmarried women express more confidence in their ability to stop childbearing than married women, whom in many contexts report pressure from husbands to have children [1].

The decision whether or not to have children is often complex and influenced by many factors. HIV-positive individuals in Africa have additional considerations to take into account when deciding whether or not to have children. These include the possibility of passing HIV from mother-to-child and the likelihood that one or both parents could die before the child reaches adulthood [2].
The majority of new HIV infections that occur in children worldwide were among children born to HIV positive mothers, who acquire HIV infection from their mothers [3]. Additionally, HIV positive patient's may manifest high-risk sexual behavior characterized by fertility intentions, multiple sexual partners, non-use of contraceptives and non-disclosure of HIV status to their sex partners [4]. So, the desire of HIV infected person to have children in the future has significant implication for the transmission of HIV to sexual partner and new born [5].

Excess fertility which is the difference between wanted total fertility and actual total fertility is greater among the HIV-positive population than the overall population [6]. Consequently, the desire and intent to have children among HIV-infected individuals may increase because of improved quality of life and survival following commencement of Anti-retroviral Treatment (ART) and reproductive health service [7]. Despite the growing importance of fertility issues for HIV-infected men and women, little is known about their actual fertility desires and intentions [8].

Most of the studies conducted in Ethiopia on fertility desire among PLWHIV are not consistent in different parts of the country because 
Page 2 of 6

fertility varies by different characteristic like religion, culture, educational status and residence urban/rural. So, this study aims to assess magnitude of fertility desire and associated factors among PLWH who are on ART.

\section{Methods}

\section{Study design and setting}

Cross sectional study design was conducted among peoples living with HIV/AIDS (PLWHIV) attending Antiretroviral Therapy (ART) in health facilities in Harari regional state in March 2013. Harari regional state is one of the nine regional states of Ethiopia located 526 Kms east of Addis Ababa. According to 2009 figures of the central statistical agency of Ethiopia, Harari regional state has an estimated total population of 209,000 which consists of 107,000 men and 102,000 women [9]. About $37.3 \%$ of the population are estimated to be rural residents. There are four governmental hospitals and eight health centers. Out of which seven of the health facilities which provide ART and pre ART follow ups. According to estimates of 2011, the project point estimate of adult HIV prevalence in the regional state was $2.8 \%$. Approximately 7,122 patients have been ever enrolled in HIV care and support programs and 4,056 have been ever enrolled to HIV. Currently there are 2,790 patients receiving ART [10].

\section{Fertility desire among people living with HIV/AIDS}

Fertility desire among People Living with HIV on ART care follow up was measured by the intension of the study participants to have a child or not in the future.

\section{Study population and sampling techniques}

Sample size was determined using the formula for two population proportion estimation using Epi-info statistics calculation for un matched case control with the assumption of 95\% certainty level, 5\% precision, and $80 \%$ power, $1: 1$ control to case ratio and considering the proportion of fertility desire among men to be $22.4 \%$ and in women $15.7 \%$ [2]. Based on this adding $10 \%$ contingency, the total sample size was 518. This sample size was distributed proportionally to their population size in to five randomly selected public health facilities (three hospitals and 2 health centers) after stratifying by sex. Finally after determining the client load at each health facility, systematic sampling was used to select the study participants.

\section{Data collection and quality control}

A structured face to face interview questionnaire was used to collect data. It includes socio demographic, child/fertility desire and knowledge on PMTCT and HIV /AIDS. The questions in the questionnaire were adopted from different literatures and Ethiopian Demographic Health Survey (EDHS). The questionnaire was translated first into the local language Amharic and Afan Oromo and back translated to English to ensure its consistency. Half day training was arranged for data collectors and supervisors about the objective of the study, method of data collection and maintenance of ethical standards. The completeness and consistency of data was assured through direct and daily supervision by the supervisors and investigators. Data coding and cleaning were performed by crossChecking the printout data for obvious errors.

\section{Data management and analysis}

Data was coded, entered, cleaned and analyzed using STATA version 11. Proportions were calculated to describe and summarize each socio demographic variable, child/fertility desire and knowledge on PMTCT and HIV /AIDS. Percentage was used to describe fertility desire. The outcome measures of fertility desire was: have fertility desire and don't have fertility desire (fertility desire $=$ Yes $/$ No).

Bivariate logistic regression was done to identify the preliminary (crude) relationship of the outcome variable (fertility desire) and different independent variables i.e socio demographic characteristics, child/fertility related characteristic and knowledge on PMTCT and HIV /AIDS. Factors which were found to be significant at PValue $<0.05$ was taken to multivariate logistic regression to see the independent factors that affect fertility desire. Odds ratio with $95 \% \mathrm{CI}$ was used to interpret and show the strength of relationship between the independent variables and fertility desire.

\section{Ethical statement}

Ethical approval was obtained from the ethical review committee of the Mekelle University, college of Health sciences with reference number ERC0231/2013. Verbal informed consent was obtained from each study participants after clear explanation about the purpose/aim, benefits, harm and duration of study. Permission to conduct the study in each health facilities was secured from the respective Health institutions in Mekelle Town.

\section{Results}

\section{Socio demographic characteristics}

A total of 518 People living with HIV/AIDS on ART were interviewed. Significant number (47.7\%) of the study participants were in the age category of $30-39$ years old. More than half $(62.2 \%)$ of the participants were followers of Orthodox religion followed by Muslim religion followers that constitutes about (25.3\%). Most (54.6\%) of the respondents were married. Regarding education, $34.2 \%$ and $32.4 \%$ were attended secondary and primary level (Table 1).

\begin{tabular}{|l|l|}
\hline \multirow{2}{*}{ Characteristics } & Frequency (\%) \\
\cline { 2 - 2 } & $\mathbf{N}=\mathbf{5 1 8}$ \\
\hline Sex & \\
\hline Wen & $259(50 \%)$ \\
\hline Age & $259(50 \%)$ \\
\hline $18-29$ years & \\
\hline $30-39$ years & $110(21.24)$ \\
\hline$>=40$ & $247(47.68)$ \\
\hline Religion & $161(31.08)$ \\
\hline Muslim & \\
\hline Orthodox & $131(25.29)$ \\
\hline Protestant & $322(62.16)$ \\
\hline
\end{tabular}


Citation: Haile F, Isahak N, Dessie A (2014) Fertility Desire and Associated Factors among People Living with HIV on ART, In Harari Regional

Page 3 of 6

\begin{tabular}{|c|c|}
\hline Education level & \\
\hline Read and write & $40(7.72)$ \\
\hline Can't read and write & $67(12.93)$ \\
\hline Primary & $168(32.43)$ \\
\hline Secondary & $177(34.17)$ \\
\hline Tertiary /University & $66(12.74)$ \\
\hline \multicolumn{2}{|l|}{ Ethnicity } \\
\hline Oromo & $150(28.96)$ \\
\hline Harari & $28(5.41)$ \\
\hline Amhara & $281(54.25)$ \\
\hline Gurage & $29(5.60)$ \\
\hline Tigre & $30(5.79)$ \\
\hline \multicolumn{2}{|l|}{ Marital status } \\
\hline Married & $283(54.63)$ \\
\hline Single & $84(16.36)$ \\
\hline Widow/widowed & $64(12.36)$ \\
\hline Divorced/separated & $87(16.8)$ \\
\hline \multicolumn{2}{|l|}{ Occupation } \\
\hline Farmer & $13(2.15)$ \\
\hline House wife & $68(12.33)$ \\
\hline Merchant & $77(14.86)$ \\
\hline Government/private employee & $147(28.38)$ \\
\hline Day laborer & $185(35.71)$ \\
\hline Unemployed & $28(5.41)$ \\
\hline \multicolumn{2}{|c|}{ Monthly Income in Ethiopian Birr } \\
\hline No income & $92(17.76)$ \\
\hline $0-500$ & $185(35.71)$ \\
\hline $501-1000$ & $80(15.44)$ \\
\hline$>1000$ & $161(31.08)$ \\
\hline
\end{tabular}

Table 1: Socio demographic characteristics of people living with HIV on ART, in Harari Regional state, Eastern Ethiopia, March 2013

\section{Fertility characteristics and sexual activity of people on ART}

Out of the 518 people interviewed, (25.9\%), (22.6\% and (25.9\%) had ever born at least one, two and greater than three children respectively in their life time. Currently, 143(27.6\%) of the study participants do not have child. Among women interviewed, (5.4\%) were pregnant. More than half of the clients, 286(55.2\%) were sexually active in the last six months prior to the survey. From those who had sexual practice in the past six months, $210(73.4 \%)$ were using condom and $61.9 \%$ of the study subjects were using family planning after diagnosed for HIV (Table 2).

\begin{tabular}{|c|c|}
\hline \multirow[t]{2}{*}{ Characteristics } & Frequency $(\%)$ \\
\hline & $N=518$ \\
\hline \multicolumn{2}{|l|}{ Number children ever born } \\
\hline No child & $133(25.68)$ \\
\hline 1 child & $134(25.87)$ \\
\hline 2 child & $117(22.59)$ \\
\hline$>=3$ child & $134(25.87)$ \\
\hline \multicolumn{2}{|l|}{ Number Alive children } \\
\hline No child & $143(27.61)$ \\
\hline 1 child & $133(25.68)$ \\
\hline 2 child & $123(23.75)$ \\
\hline$>=3$ child & $119(22.97)$ \\
\hline \multicolumn{2}{|l|}{ Number of children want to have $(n=291)$} \\
\hline 1 child & $110(37.80)$ \\
\hline 2 child & $144(49.48)$ \\
\hline$>=3$ child & $37(12.71)$ \\
\hline \multicolumn{2}{|l|}{ Reason want for more children } \\
\hline Want at least 1 child & $80(27.4)$ \\
\hline Children are important & $50(17.12)$ \\
\hline original desire unchanged & $28(9.59)$ \\
\hline Improved health with ART* & $35(11.99)$ \\
\hline Sex preference & $57(19.52)$ \\
\hline Desire for HIV negative child & $42(14.38)$ \\
\hline \multicolumn{2}{|l|}{ Reason don't want for more children } \\
\hline Have desired number of children & $150(65.79)$ \\
\hline Fear of $\mathrm{MTCT}^{*}$ & $11(4.82)$ \\
\hline Don't have adequate income & $50(21.93)$ \\
\hline Child bearing may aggravate my health & $17(7.46)$ \\
\hline \multicolumn{2}{|l|}{ Partner fertility desire } \\
\hline Yes & $209(40.35)$ \\
\hline No & 88 (16.99) \\
\hline Don't know & $42(8.11)$ \\
\hline Don't have partner & $179(34.56)$ \\
\hline \multicolumn{2}{|l|}{ Currently Pregnant } \\
\hline Yes & $14(5.38)$ \\
\hline No & $245(94.62)$ \\
\hline \multicolumn{2}{|l|}{ Use family planning } \\
\hline Yes & $320(61.78)$ \\
\hline
\end{tabular}


Citation: Haile F, Isahak N, Dessie A (2014) Fertility Desire and Associated Factors among People Living with HIV on ART, In Harari Regional

Page 4 of 6

\begin{tabular}{|l|l|}
\hline No & $159(30.69)$ \\
\hline Don't know & $39(7.53)$ \\
\hline Type of family planning & \\
\hline Abstinence & $14(4.38)$ \\
\hline Condom & $194(60.62)$ \\
\hline Pills(OCP)* & $9(2.81)$ \\
\hline Injectables & $58(18.13)$ \\
\hline IUCD* & $29(9.06)$ \\
\hline Implants & $16(5)$ \\
\hline Sexual activity in the last 6 month & \\
\hline Yes & $286(55.21)$ \\
\hline No & $232(44.79)$ \\
\hline Use condom & \\
\hline Yes & $210(73.43)$ \\
\hline No & $76(26.57)$ \\
\hline
\end{tabular}

Table 2: Fertility characteristics and sexual activity of people living with HIV, on ART in Harari Regional state, Eastern Ethiopia 2013

${ }^{*}$ MTCT $=$ mother to child transmission

${ }^{*} \mathrm{ART}=$ Antiretroviral therapy

${ }^{*} \mathrm{IUCD}=$ Intra uterine contraceptive device

${ }^{*} \mathrm{OCP}=$ Oral contraceptive pill

Concerning fertility desire of the study participants, 291(56.2\%) had a desire to have a child in the future. From totally interviewed people living with HIV, $59.5 \%$ of men and $52.9 \%$ of women have fertility desire to have a child in the future.

\section{Factors associated with fertility desire among people on ART}

In bivariate (crude) analysis, results revealed that age category greater than or equal to 40 years, widowed and divorced, individuals who have ever born three or more children, presence of alive children, use of family planning, partner fertility desire, sexually active in the previous six months were found to be statistically significant (Table 3).

\begin{tabular}{|c|c|c|c|}
\hline Characteristics & $\begin{array}{ll}\text { Crude } & \text { OR } \\
(95 \% \mathrm{Cl}) & \end{array}$ & $\begin{array}{l}\text { Adjusted } \quad \text { OR } \\
(95 \% \mathrm{Cl})\end{array}$ & P-value \\
\hline \multicolumn{4}{|l|}{ Sex } \\
\hline Men & 1 & 1 & \\
\hline Women & $0.77(0.54-1.08)$ & $\begin{array}{l}0.418 \\
(0.23-0.75)^{\star}\end{array}$ & $P<0.0001$ \\
\hline \multicolumn{4}{|l|}{ Age } \\
\hline $18-29$ years & 1 & 1 & \\
\hline $30-39$ years & $\begin{array}{l}0.39 \\
(0.234-0.653)^{*}\end{array}$ & $\begin{array}{l}0.39 \\
(0.19-0.82)^{*}\end{array}$ & $P<0.0001$ \\
\hline
\end{tabular}

\begin{tabular}{|c|c|c|c|}
\hline$>=40$ & $0.20(0.14-0.34)^{*}$ & $\begin{array}{l}0.15 \\
(0.06-0.35)^{*}\end{array}$ & 0.002 \\
\hline \multicolumn{4}{|l|}{ Marital status } \\
\hline Married & 1 & & \\
\hline Single & $\begin{array}{l}3.52 \\
(1.862-6.668)^{*}\end{array}$ & & \\
\hline Widow/widowed & $\begin{array}{l}0.233 \\
(0.128-0.427)^{*}\end{array}$ & & \\
\hline Divorced/separated & $\begin{array}{l}0.357 \\
(0.217-0.589)^{*}\end{array}$ & & \\
\hline \multicolumn{4}{|l|}{$\begin{array}{l}\text { Number children ever } \\
\text { born }\end{array}$} \\
\hline No child & 1 & 1 & \\
\hline 1 child & $0.29(0.15-0.55)^{*}$ & $\begin{array}{l}0.24 \\
(0.11-0.52)^{*}\end{array}$ & $P<0001$ \\
\hline 2 child & $0.10(0.05-0.17)^{*}$ & $\begin{array}{l}0.07 \\
(0.03-0.15)^{*}\end{array}$ & $P<0001$ \\
\hline$>=3$ child & $0.05(0.03-0.10)^{*}$ & $\begin{array}{l}0.037 \\
(0.02-0.09)^{*}\end{array}$ & 0.0185 \\
\hline \multicolumn{4}{|l|}{$\begin{array}{l}\text { Number } \\
\text { children }\end{array}$ of Alive } \\
\hline No child & 1 & & \\
\hline 1 child & $3.34(1.83-6.09)^{*}$ & & \\
\hline 2 child & $\begin{array}{l}9.21 \\
(5.05-16.81)^{*}\end{array}$ & & \\
\hline$>=3$ child & $\begin{array}{l}21.21 \\
(11.16-40.32)^{*}\end{array}$ & & \\
\hline \multicolumn{4}{|l|}{ Partner fertility desire } \\
\hline Yes & 1 & 1 & \\
\hline No & $0.01(0.01-0.03)^{*}$ & $\begin{array}{l}0.01 \\
(0.004-0.03)^{*}\end{array}$ & $P<0.0001$ \\
\hline Don't know & $0.08(0.04-0.17)^{*}$ & $\begin{array}{l}0.046 \\
(0.02-0.12)^{*}\end{array}$ & 0.024 \\
\hline Don't have partner & $\begin{array}{l}0.131 \\
(0.08-0.22)^{*}\end{array}$ & $\begin{array}{l}0.10 \\
(0.05-0.57)^{*}\end{array}$ & $P<0.0001$ \\
\hline \multicolumn{4}{|l|}{$\begin{array}{l}\text { Use } \\
\text { contraceptive }\end{array}$ family } \\
\hline Yes & 1 & 1 & \\
\hline No & $0.92(0.62-1.35)$ & $\begin{array}{l}2.96 \\
(1.46-5.99)^{*}\end{array}$ & $P<0.024$ \\
\hline Don't know & $0.35(0.17-0.71)^{*}$ & $1.46(0.48-4.41)$ & \\
\hline \multicolumn{4}{|l|}{$\begin{array}{l}\text { Sexual activity in the } \\
\text { last } 6 \text { month }\end{array}$} \\
\hline Yes & 1 & 1 & \\
\hline
\end{tabular}




\section{No} $0.39(0.27-0.56)^{*}$

0.24

$(0.12-0.48)^{*}$

Table 3: Factors that affect fertility desire among people living with HIV on ART, in Harari regional state, Eastern Ethiopia, 2013

In multiple logistic regression analysis, sex, age, number of children ever born, partner fertility desire, use of family planning and sexual activity in the previous six months were found to be statistically significant with fertility desire. Women were $58 \%$ times lesser fertility desire when compared with men. Individuals with age category 30-39 and greater than 40 years were $39 \%$ and $15 \%$ lesser fertility desire respectively than age 18-29 years. Ever presence of one child, two children and three or more children were $23 \%, 6.6 \%$ and $3.6 \%$ less fertility desire than those who doesn't have a child. Concerning partner fertility desire, individuals whose partner had no fertility desire were $1.2 \%$ lesser fertility desire when compared with clients whose partners had fertility desire. Additionally, respondents who do not use family planning were 3 times higher to have fertility than clients who use family planning. Finally individuals who don't have sexual activity in the past six months were $23.7 \%$ less likely to have fertility desire than their counter parts (Table 3 ).

\section{Discussion}

According to findings of this study, more than half of men (59.5\%) and women (52.9\%) living with HIV have fertility (child) desire. This was consistent with studies conducted in Mekelle town, northern Ethiopia and south Africa which reported that $66.1 \%$ of women living with HIV/AIDS in Mekelle -Ethiopia and $57 \%$ of men $45 \%$ of women living with HIV/AIDS in South Africa have fertility desire $[9,10]$. But similar study done in south Wollo, Ethiopia is quite different from our study which reported that $18.3 \%$ of people living with HIV have desire to have children. This may be due to lack of knowledge on PMTCT service since the study was conducted 6 years ago where there was no awareness about mother to child transmission of HIV and it also includes only married individuals. Another study done in northern Nigeria was also found concordant results which reported that $65.5 \%$ of women and $61.2 \%$ of men have a desire to have another child which shows slight increment in fertility desire [11]. This may be due to the fact that majority of the study subjects in Nigeria were Muslims, which allowed polygamy and other reason that may increase family size in competition between wives to have as many children as possible, especially sons, as this would increase their share of the husband's estate and property [11].

In our study, sex was found as one of the factors that affect fertility desire among people living with HIV/AIDS. Accordingly, women have $58 \%$ times lesser fertility desire when compared with men which is consistent with the study conducted in Mekelle town, Ethiopia, South Wallo, Ethiopia, Nekemte, Ethiopia and Uganda [12-15]. This may be explained by the reason that women had fear of vertical transmission of the virus to the newborn and they think that their HIV infection may be aggravated and get worse due to pregnancy but men want to have more child specially sons because they want to live something of themselves.

Individuals in the older age group had a lower fertility desire compared to the younger age groups i.e respondents in the age category of 30-39 and greater than or equal to 40 years old have lesser fertility desire as compared with those whose age category was
18-29 years old. Similar studies done in Addis Ababa, Ethiopia Nekemte, Ethiopia and Uganda reported similar findings [14-16].

This study indicated that respondents by whom the number of children ever born in their life time was one child, two child and greater than or equals to three children have lesser fertility desire when compared with those respondents who have no child in their life time. A study done in Nekemte, Ethiopia has found similar findings that individuals with two and more children has less fertility desire than those who didn't have [15].

Partner fertility desire was also another determinant of fertility (child) desire i.e. respondents whose partners had no fertility desire were less likely to have fertility desire when compared with their counter parts. Similar studies done in Ethiopia came up with similar findings $[10,17,18]$. This could be because of the better opportunity to discuss about fertility related decisions among couples.

Family planning is another factor that affects fertility desire of people living with HIV. Consequently, respondents who do not use family planning were 3 times higher to have fertility desire in the future when compared with clients who use family planning.

Respondents who have sexual activity in the past six months, among clients who do not have sexual activity in the past six month were $24 \%$ times lesser to have fertility desire when compared with respondents who have sexual activity in the past six months which is similar with the study done in Tanzania [17].

The limitation of this study is that it uses only client's view (individual level) to assess fertility desire without considering the community level factors (sociological factors) that may significantly affect fertility desire.

In conclusion there is high fertility desire among people living with HIV/AIDS and the factors that affect fertility desire were: sex, age, number of children ever born, partner fertility desire, use of family planning and sexual activity in the past six months. Consequently, this implies the need for reproductive planning (PMTCT and family planning) and counseling for clients in HIV care settings in order to meet PLWHIV diverse reproductive intentions for those wishing to have children and those wishing to avoid having a child. Additionally, further research should be done to investigate the individual and community level (sociological factors) that may affect fertility desire of PLWHIV.

\section{Authors' contributions}

Nesredine Isahak: Involved in proposal writing, designing, and recruitment and training of Supervisors and data collectors, analysis and write-up and in all stages of the project implementation. He did most of the analysis and write up of the paper.

Fisaha Haile: contributed in the designing of the methodology, lead investigator and involved in designing of project proposal, design of questionnaires, supervision and involved in the analysis stage of the project and final approval of the paper.

Awrajaw Dessie: contributed in the designing of the methodology, lead investigator and involved in designing of project proposal, design of questionnaires, supervision and involved in the analysis stage of the project and final approval of the paper. 
Citation: Haile F, Isahak N, Dessie A (2014) Fertility Desire and Associated Factors among People Living with HIV on ART, In Harari Regional State, Eastern Ethiopia. J Trop Dis 2: 137. doi: 0.4172/2329-891X.1000137

Page 6 of 6

\section{Acknowledgement}

The Authors are grateful to the Mekelle University, College of Health Sciences, Tulane University and Harari Regional state health bureau for sponsoring this research project. We also extend sincere appreciation to all health workers of Haramaya University, Hiwot Fana Specialized Referral Hospital, Jugol Hospital, Police Hospital and Jinela health center, who helped us during data collection. Last but not least, we are grateful to the data collectors and supervisors for carefully undertaking of their tasks.

\section{References}

1. Cooper D, Harries J, Myer L, Orner P, Bracken H, et al. (2007) "Life is still going on": reproductive intentions among HIV-positive women and men in South Africa. Soc Sci Med 65: 274-283.

2. Newell ML, Brahmbhatt H, Ghys PD (2004) Child mortality and HIV infection in Africa: a review. AIDS 18 Suppl 2: S27-34.

3. Newell ML (2000) Vertical transmission of HIV-1 infection. Trans R Soc Trop Med Hyg 94: 1-2.

4. Kline A, Strickler J, Kempf J (1995) Factors associated with pregnancy and pregnancy resolution in HIV seropositive women. Soc Sci Med 40: 1539-1547.

5. Chen JL, Philips KA, Kanouse DE, Collins RL, Miu A (2001) Fertility desires and intentions of HIV-positive men and women. Fam Plann Perspect 33: 144-152, 165

6. Bankole A, Ann EB, Kumbutso D (2009) Fertility Preferences and Contraceptive Behaviors by HIV Status for Women and Men in 19 SubSaharan African Countries. International Union for the Scientific Study of Population Conference, Marrakech, Morocco.

7. Harries J, Cooper D, Myer L, Bracken H, Zweigenthal V, et al. (2007) Policy maker and health care provider perspectives on reproductive decision-making amongst HIV-infected individuals in South Africa. BMC Public Health 7: 282.
8. Bankole A, Biddlecom AE, Dzekedzeke K (2011) Women's and men's fertility preferences and contraceptive behaviors by HIV status in $10 \mathrm{sub}$ Saharan African countries. AIDS Educ Prev 23: 313-328.

9. Federal democratic republic of Ethiopia (2013) Ministry of Health. WHO.

10. Harari regional health beroue $/ 2012$ report.

11. Iliyasu Z, Abubakar IS, Kabir M, Babashani M, Shuaib F, et al. (2009) Correlates of fertility intentions among HIV/AIDS patients in northern Nigeria. Afr J Reprod Health 13: 71-83.

12. Alemayehu B, Aregay A (2011) Desire to procreate among people living with HIV/AIDS: Determinants in Ethiopia: A cross-sectional Study. J AIDS HIV Res 4: 128-135.

13. Kakaire O, Osinde MO, Kaye DK (2010) Factors that predict fertility desires for people living with HIV infection at a support and treatment centre in Kabale, Uganda. Reprod Health 7: 27.

14. Beyeza-Kashesya J, Ekstrom AM, Kaharuza F, Mirembe F, Neema S et al. (2010) My partner wants a child. A cross-sectional study of the determinants of the desire for children among mutually disclosed serodiscordant couples receiving care in Uganda. BMC Public Health 10: 247.

15. Regassa T, Fantahun M (2012) Fertility Desire and Reproductive Health Care Needs of Men and Women Living with HIV/AIDS in Nekemte, East Wollega, Ethiopia. STAR Journal 1:31-38.

16. Ethiopia Demographic and Health Survey 2011 (2012) Central Statistical Agency Addis Ababa, Ethiopia ICF International Calverton, Maryland, USA March 2012.

17. Mmbaga EJ, Leyna GH, Ezekiel MJ, Kakoko DC (2013) Fertility desire and intention of people living with HIV/AIDS in Tanzania: a call for restructuring care and treatment services. BMC Public Health 13: 86.

18. Cooper D, Moodley J, Zweigenthal V, Bekker LG, Shah I, et al. (2009) Fertility intentions and reproductive health care needs of people living with HIV in Cape Town, South Africa: implications for integrating reproductive health and HIV care services. AIDS Behav 13 Suppl 1: $38-46$. 